passive smoking. Clinical and Investigative Medicine, 3, $17-42$.

World Health Organization Heads of Centres Collaborating in WHO Co-ordinated Studies on Biological
Aspects of Mental Illness (1990) Prophylatic Use of Anticholinergics in Patients on Long-term Neuroleptic Treatment. A Consensus Statement. British Journal of Psychiatry, 156, 412.

\title{
Audit in psychotherapy: the concept of Kaizen
}

\author{
M. M. Feldman, Consultant Psychotherapist, The Maudsley Hospital, \\ London SE5 8AZ
}

When any organisation is exposed to pressure to change, this not only mobilises considerable anxieties within the organisation but calls a variety of defensive operations into play. The work of Jaques (1955) and Menzies Lyth $(1959,1988)$ has demonstrated that this can result in the central problem ceasing to be the focus of attention, with primitive defensive mechanisms (often of an obssesional or paranoid kind) being mobilised. This process may either lead to energy being devoted to isolated elements of the situation, or staff withdrawing into a state of passivity and hopelessness. Indeed, Jaques has observed that when changes are imposed on an institution in a way which fails to take account of the functions that existing structures serve in relation to the deeper needs and anxieties of those working within the institution, such changes are likely to be resisted, and may even fail.

When, by contrast, the needs, motivation and anxieties of the members of the institution are properly taken into account, and changes are introduced by working with staff, they are more likely to succeed, and efficiency and morale may improve. The Japanese concept of 'Kaizen', which has proved of value in industry, involves the application of some of these notions.

One response of the present government to the serious problems facing the NHS has been to '... redefine the problems of the NHS as the need to find ways to control costs in the face of limitless demands for health care, identify value for money, and increase consumer choice,' an interpretation which Plamping (1991) describes as 'highly selective'.

The pressure to subject clinical work (and teaching) within different branches of medicine to audit has, so far, had a number of effects - some useful, but many of them wasteful. It has aroused unease and confusion among some clinical staff, and has led to plans for a considerable expenditure in manpower and resources. This investment may prove costeffective over a period of time, but its value is far from proven. The reservations about these moves are not only the response to change and innovation, nor do they simply express the defensiveness of a group of professionals unused to this type of scrutiny. Good medical practice has always involved the constant review of procedures, though in ways very different from those being proposed. The fact that there is scope for improving the range, depth and effectiveness of such scrutiny is not in dispute.

There is a danger, however, that the approach to audit which is being supported by central government, which represents an experiment not previously implemented in this field, may cause serious damage to the morale and effective functioning of staff within a number of areas in medicine. The basic philosophy of attempting systematically to monitor what is actually done, its cost, and (as far as feasible) its effectiveness has much to commend it. However the methods by which these highly complex tasks are to be carried out are by no means clearly worked out, and require thoughtful co-operation between the representatives of central government, local management, and clinicians.

Some clinicians, however, have responded to pressures from inexperienced and unsophisticated management (themselves under pressure) by resorting to equipment and systems of data collection which are expensive, and which may temporarily satisfy local managers that "something is being done in audit', but which can actually contribute little towards an improvement in the service. There is often a sense of threat, an adversarial atmosphere, the notion of managers 'watching' in a rather persecutory fashion, and having to be appeased by data of little real value.

By contrast, the Japanese concept of 'Kaizen' places the emphasis on process rather than outcome, as the most effective means of improving a service (or product). It requires a number of conditions: "Managers must create an environment in which people are enthusiastic to identify deficiences and work together to right them. Fear must be abolished" (Smith, 1990). The steps in the process must first be charted and measured. This may involve the use of organised data, and/or statistical techniques, and this exercise may be revelatory in itself. An attempt is then made to identify where improvements can be made, and further assessment or measurements made after these improvements have been instituted, and so on. 
The aim is to shift the whole process towards greater quality. (Smith, 1990; Berwick, 1989).

This approach seems to have much to commend it, and invokes a very different climate within any organisation in which it might be applied. While the concept of 'Kaizen' has primarily been developed in industry, with the ultimate aim of increasing productivity, and thus profitability, it may be useful to consider adapting such an approach for use within different branches of medicine. This will be illustrated by offering an outline of the way this might be applied to a psychotherapy service within a postgraduate teaching hospital in South East London.

\section{'Kaizen' in psychotherapy}

The way in which out-patient psychotherapy services tend to be organised within the NHS lends itself admirably to the monitoring of different 'modules' of the process of referral, assessment, and treatment. Within each of the modules it is possible to delineate broad aims, methods of monitoring routinely collected data, and more complex clinical assessments and discussions relevant to that stage of the process.

The basic structure for such an audit has been established within the Psychotherapy Unit at the Maudsley Hospital, and this will be briefly described. The modules which are considered in turn are: referral, assessment, treatment, and follow-up. There is a further, separate module relating to the teaching function of the Unit. It is important to distinguish between different types of data which are collected by different methods. Much basic information relating to the activity of the Unit is routinely entered into a computer database by the secretarial staff, using specially designed software, and represents little additional work. In fact it facilitates the storage and retrieval of data necessary for the efficient running of the Unit, and there has been a considerable improvement in the speed and convenience of routine data entry and retrieval, with an accompanying rise in morale.

Monthly audit meetings have been instituted in which each module is considered in rotation. At each meeting, information relating to different levels of complexity are examined. As part of this exercise, the 'broad aims' or strategy relating to each module (referral, assessment, treatment, follow-up and teaching) are provisionally formulated. This formulation will periodically be examined, and modified in the light of experience, taking into account changing demands and changes in policy.

Each meeting is presented with 'routine data' referring to the module under discussion (say, referral), collected by the secretarial staff as part of the routine work of the Unit, collated by a simple computer programme which prints out a summary. The 'routine data' relating to previous six-month periods is also made available for comparison, as a discussion of any apparent trends may form part of the meeting, or merit more detailed study.

Once a year the data will be examined in greater breadth and detail - relating the intra-modular data to data from other modules. For example, examination of data concerning referral and the outcome of assessment may indicate that many of the referrals are not considered suitable for the types of psychotherapy which this Unit provides. If (say) it emerges that a high proportion of GP referrals are rejected (in contrast to referrals by consultant psychiatrists), then a number of policy options follow.

(a) The Unit may decide to accept this situation, seeing this as a useful consultation service for GPs.

(b) Alternately, the decision may be only to assess patients screened by consultant psychiatrists.

(c) This finding may lead to more active liaison with potential referring GPs to clarify the types of patient likely to be accepted for treatment.

(d) The Unit may decide to modify its assessment procedure, or widen its treatment options, to meet the evident need of this group of referrers.

Finally, the main part of the audit meeting is devoted to a discussion of clinical issues relating to that module. Thus there might be a discussion of issues based on the referral of a group of patients of a particular sort, to consider the treatment problems raised by such patients, or a discussion of the issues raised by the referral of a particularly difficult but interesting patient. It is in fact the systematic discussion of clinical problems and decisions about referrals to the Unit which engage the interest and attention of the staff, serve to clarify Unit procedures and policy, and are likely to identify ways in which the quality of the service can be improved.

(It will be apparent that 'research', as a formal discipline has not been included in this schema. There is undoubtedly a strong argument for the development and application of appropriate research methods in psychotherapy. While the system of audit proposed makes available a good deal of information which could be the basis for further formal research projects, and indeed the audit meetings are likely to generate ideas for further research, it seems preferable that these projects should be designed and carried out by designated members of staff with a particular interest in, and responsibility for them. It does not seem useful to confuse the process of audit with more complex research aims. This seems generally to result in the accumulation of large quantities of data of uncertain value, for which no-one has specific responsibility.) 
As an essential part of the concept of 'Kaizen', the process of audit will itself be constantly subject to review. There will be changes in the issues it is most useful to consider, in methods, and in the way in which such discussions could influence clinical practice. It is important to regard the process as being largely experimental, and any attempt authoritatively to impose rules and procedures is likely to be based on a proper constructive understanding of the subject, and thus unlikely to serve the purposes behind this exercise.

\section{References}

BERWICK, D. M. (1989) Continuous improvement as an ideal in health care, New England Journal of Medicine, $320,53-56$.
JAQUES, E. (1955) Social systems as a defence against persecutory and depressive anxiety. In New Directions in Psycho-Analysis (eds M. Klein, P. Heimann, and R. E. Money-Kyrle) London: Tavistock Publications; paperback, Tavistock Publications, 1971.

MENZiEs LYTH, I. E. P. (1959) A case-study in the functioning of social systems as a defence against anxiety. A report on the nursing service of a general hospital. Human Relations, 13, 95-121.

-(1988) A psychoanalytic perspective on social institutions. In Melanie Klein Today (ed. E. Spillius) London: Routledge.

Plamping, D. (1991) The new NHS: Better to go forwards than backwards, Editorial British Medical Journal, 302, 737-738.

SMITH, R. (1990) Medicine's needs for Kaizen: putting quality first, Editorial, British Medical Journal, 301, 679-80.

\title{
Admission profile: towards community based services
}

\author{
R. S. Augustine, Consultant Psychiatrist and Psychiatric Tutor; P. N. KuRIAN, \\ Senior House Officer; and A. MichaEl, Senior House Officer, St Fintan's Hospital, \\ Portlaoise, Co. Laois, Republic of Ireland
}

This audit examined 65 consecutive admissions to a psychiatric hospital in the Irish Midlands over six months. The admissions came from a defined sector with a total population of 39,000 . In the year prior to the study major changes in the delivery of psychiatric care in the sector were instituted. These changes included the introduction of admission guidelines and extra resources in the community. The general practitioners who see mental illness at first contact were informed of these changes. Attempts were made by the sector psychiatrist team to screen for appropriateness of admission with regard to the special groups such as alcoholics, the aged and the mentally handicapped.

The extra resources for maintaining patients in the community were a new mental health centre (day hospital and day centre) and more out-patient clinics as well as hostel accommodation.

We felt that it was an appropriate time to examine the admission profile of patients admitted to the psychiatric hospital. The focus was on the sociodemographic and admission characteristics of patients who were admitted from this sector from January to June 1990.

\section{The study}

Patients were diagnosed by the auditing team according to ICD-9 classification. These diagnoses were

also used for the hospital in-patient reporting system for statistical purposes. We examined all the admissions over the months from 1 January 1990 to 30 June 1990.

A schedule was devised to look at selected sociodemographic characteristics and admission patterns as well as patient support systems. The source of support was taken to include the presence and availability of a relative or a key person as well as their appropriate concern for the patient's welfare. The level of support was rated according to the clinical judgement of the auditing team. An estimate of the general level of out-patient services during the same period was also carried out.

\section{Findings}

Sector population

Community services

Number of out-patients

Number of day hospital patients

Number of day centre patients

Number of general hospital consultations

Total

In-patient service

Number of patients admitted to the Acute Psychiatric Unit
$=39,000$

$=256$

$=175$

$=70$

$=27$

$=528$

$=65$ 